\title{
Prevalence and factors associated with exclusive breastfeeding among rural mothers of infants less than six months of age in Southern Nations, Nationalities, Peoples (SNNP) and Tigray regions, Ethiopia: a cross-sectional study
}

Dawit Hagos $^{1 *}$ and Amare Worku Tadesse ${ }^{2,3}$

\begin{abstract}
Background: Exclusive breastfeeding (EBF) is the global recommended nutrition for infants less than 6 months of age. The prevalence of exclusive breastfeeding in Ethiopia is much lower than the recommendations of World Health Organization (WHO). This study aimed to assess the prevalence and associated factors of EBF among rural mothers of infants less than 6 months of age in two regions, Southern Nations, Nationalities and Peoples (SNNP) and Tigray Regions, of Ethiopia.

Methods: The research was based on the secondary data analysis of community-based cross-sectional study conducted in 56 rural woredas (districts) in two regions of Ethiopia for impact evaluation of Alive \& Thrive multiyear project. The 24-h recall dietary data were collected from 600 mother-infant dyads where the infant was less than 6 month of age, using multistage cluster sampling technique and 584 dyads were found eligible for analysis. Bivariate and multivariable logistic regressions were applied to identify the associated factors of exclusive breastfeeding.

Results: The prevalence of EBF of infants less than 6 months of age was $88.0 \%$ ( $95 \% \mathrm{Cl} 84.9,90.4 \%)$. The odds of practicing EBF were significantly higher among infants less than 2 months of age (AOR 4.47, 95\% Cl 2.41, 8.27), married mothers (AOR 4.35, 95\% Cl 1.50, 12.67), mothers who gave birth in health facilities (AOR 2.07, 95\% Cl 1.15, 3.73) and mothers who received breastfeeding counseling during pregnancy (AOR 2.23, 95\% Cl 1.26, 3.96).

Conclusions: The prevalence of EBF was relatively high when compared with previous studies in Ethiopia but close to the $\mathrm{WHO}$ recommendations of $90 \%$. Infant age, marital status of mothers, delivery place and breastfeeding counseling during pregnancy were identified as factors associated with EBF practices in $24 \mathrm{~h}$ preceding the survey. Devising appropriate strategies on breastfeeding messaging/counseling and support in addressing poor breastfeeding practices through existing government-led health intervention packages are recommended.
\end{abstract}

Keywords: Exclusive breastfeeding, Rural, SNNPR, Tigray, Ethiopia

\footnotetext{
* Correspondence: dawitmai@yahoo.com

${ }^{1}$ Save the Children South Sudan, Juba, South Sudan

Full list of author information is available at the end of the article
}

(c) The Author(s). 2020 Open Access This article is licensed under a Creative Commons Attribution 4.0 International License, which permits use, sharing, adaptation, distribution and reproduction in any medium or format, as long as you give appropriate credit to the original author(s) and the source, provide a link to the Creative Commons licence, and indicate if changes were made. The images or other third party material in this article are included in the article's Creative Commons licence, unless indicated otherwise in a credit line to the material. If material is not included in the article's Creative Commons licence and your intended use is not permitted by statutory regulation or exceeds the permitted use, you will need to obtain permission directly from the copyright holder. To view a copy of this licence, visit http://creativecommons.org/licenses/by/4.0/ The Creative Commons Public Domain Dedication waiver (http://creativecommons.org/publicdomain/zero/1.0/) applies to the data made available in this article, unless otherwise stated in a credit line to the data. 


\section{Background}

Global recommendations for optimal infant feeding include exclusively breastfeeding (EBF) for the first 6 months of their life [1-4]. Research findings have shown up to a $13 \%$ reduction in infant mortality rate can be achieved through the practices of EBF in low income countries, including Bangladesh and Pakistan [5], in addition to infant and maternal health benefits $[2,6,7]$.

Despite the well recognized multiple benefits of exclusive breastfeeding, the coverage of exclusive breastfeeding is very low globally as compared to the WHO recommendation of $90 \%$ coverage. Trend data analysis on prevalence of exclusive breastfeeding among infants less than 6 months of age in developing countries indicated that only $39 \%$ of the infants were exclusively breastfed in 2010 [8]. The same study has estimated the prevalence of EBF in Africa and Asia as 35 and 41\% [8].

In Ethiopia, breastfeeding is almost universal practice among mothers but the proportion of exclusively breastfed infants less than 6 months of age was low at $58 \%$ in 2016 [9]. Hence, the nation may benefit less from the multiple advantages of exclusive breastfeeding for infants, mothers and the nation in general.

Exclusive breastfeeding of infants less than 6 months of age is associated with many individual, group and societal level factors that can be further classified as infant, maternal and household characteristics, and health service-related factors [10-13]. In Ethiopia, infant characteristics including age and prelacteal feeds; maternal characteristics such as age, education, occupation, and marital status; and health facility characteristics including place of delivery, antenatal and postnatal care and counselling were previously reported to influence EBF [14-18]. Strategies to promote exclusive breastfeeding are desired at the national, health facility and community levels [4].

Therefore, this study aimed to assess the prevalence of exclusive breastfeeding among infants less than 6 months of age in the past $24 \mathrm{~h}$ preceding the survey date and to determine the factors associated with EBF in two regions of Ethiopia, Southern Nations, Nationalities and Peoples (SNNP) and Tigray regions.

\section{Methods}

This study was based on analysis of the secondary data from the impact evaluation of Alive \& Thrive project implemented in Ethiopia in collaboration with Ethiopian Ministry of Health, Integrated Family Health Program (IFHP) and other local organizations. This multi-year project (2009-2014) was implemented in 89 woredas (local administrative units similar to districts) of the two regions of Ethiopia: SNNPR (54 woredas) and Tigray Region (35 woredas). Baseline, mid-term evaluation and impact evaluation studies were conducted based on the project time frame.

As part of the impact evaluation, the data were collected in SNNP and Tigray regions within the frame work of an impact evaluation with adequacy design that captures changes overtime in the absence of a control group. Hence, community-based cross-sectional study design was deployed using multistage cluster sampling techniques to generate the primary data. A total of 75 enumeration areas (EA) were selected for the final evaluation of the project from 56 target woredas that included 37 woredas from SNNPR and 19 woredas from Tigray Region. The study population was infants less than 6 months of age, living in 75 enumeration areas of the 56 woredas and data were collected from 600 sample infant mother dyads. All data were obtained from face to face home interview with mothers of infants less than 6 months of age and 584 of them found eligible for analysis. The incomplete data of 16 infant mother dyads were excluded from analysis due to missing data on important variables of the study.

The sample size required for this study was calculated using the formula to estimate single population proportion for objective 1 based on the EDHS 2011 finding of $52 \%$ prevalence of exclusive breastfeeding for 6 months [19] with an estimated missing data of $10 \%$ that resulted sample size of 427 .

The sample sizes for the second objective was calculated based on previous findings of prevalence of prelacteal feeding of $19.9 \%$ [14], prevalence of initiation of breastfeeding within the first $1 \mathrm{~h}$ of birth (72.3\%) and mothers receiving advice about EBF (90.2\%) [10]. The sample size calculated for EBF counselling during antenatal care $(\mathrm{ANC})$, delivery and postnatal care (PNC) (520 infants less than 6 months of age) was the highest sample size and taken as the sample size for both objective 1 and 2. However, all the 600 data sets of mothers who had infants less than 6 months of age in the end line evaluation of 2014 were considered in this analysis. The investigator checked all the data for completeness and accuracy. Data set of 584 infants was found eligible for analysis after data cleaning. The 24-h dietary recall method was used to measure exclusive breastfeeding.

\section{Variables}

The dependent variable for this study was exclusive breastfeeding of infants less than 6 months of age based on the WHO definition as the proportion of infants less than 6 months of age who are fed with breast milk exclusively without any other drinks or foods in the past $24 \mathrm{~h}$ with the exception of oral rehydration salt (ORS), vitamin and mineral supplements, or medicine [20].

A wide range of independent variables were assessed as potential factors that influence exclusive 
breastfeeding. Based on conceptual framework described by Hector [13], we studied age and sex of infant, maternal age, education, marital status, occupation, knowledge of mothers in EBF, infant feeding practices and birth experience. In addition, health facility services variables including ANC and PNC, breastfeeding counseling in the health facilities, place of delivery, type of delivery and breastfeeding support were studied.

\section{Statistical analysis}

Data were analysed using SPSS 20 for Windows statistical software package (International Business Machines Corporation, New York, NY, USA). Descriptive statistics were applied for sociodemographic variables describing the characteristics of infants, mothers and the households, and to determine the prevalence of exclusive breastfeeding practices, timely initiation of breastfeeding and prelacteal feeding. Proportions were compared by exclusive breastfeeding using correlation of independent variables. To determine the association between independent variables and the dependent variable (EBF), bivariate logistic regression was carried out for selected variables with the outcome variable (EBF). Hosmer and Lemeshow test for goodness of fit was conducted and the model was found fit with $P$ - value $>0.05$ (chi-square $6.266, p=0.618$ ). Variables with a $p$ - value less than 0.2 on bivariate logistics regression analysis were included in the multivariable logistic regression to determine associated factors with EBF. The statistical significance was determined using odds ratio of $95 \%$ confidence interval with $p$ - value less than 0.05 .

\section{Results}

\section{Sociodemographic characteristics}

Data of 584 mothers having children less than 6 months old were analyzed and the sociodemographic characteristics were depicted in Table 1. About one third (32\%) of the mothers were young (15-24 years) and the median age of the mothers was 27 years (mean $27.8+6.4$ years). Majority $(95.9 \%)$ of the mothers were married. More than half $(54 \%)$ of the mothers had completed primary school or above. Thirty-seven percent of the infants were two to 3 months old and the median age was 2 months (Table 1).

\section{Health service characteristics}

As indicated in Table 2, most (90.4\%) of the mothers attended antenatal care during their last pregnancy and more than half $(50.7 \%)$ of them had four or more visits. However, only $58.4 \%$ of the mothers received breastfeeding counseling during their pregnancy of the index child. About $55 \%$ (54.7\%) of the mothers delivered in the health facility while the rest of the mothers gave birth at home. The majority $(97.8 \%)$ of the mothers had a vaginal
Table 1 Sociodemographic characteristics of mothers of infants less than 6 months of age, Tigray \& SNNPR, $(n=584)$

\begin{tabular}{|c|c|c|}
\hline Variables & Numbers $(\boldsymbol{n})$ & Percent (\%) \\
\hline \multicolumn{3}{|l|}{ Age of mothers in years } \\
\hline $15-24$ & 186 & 32.0 \\
\hline $25-29$ & 158 & 27.2 \\
\hline $30-34$ & 124 & 21.3 \\
\hline $35-49$ & 113 & 19.5 \\
\hline \multicolumn{3}{|l|}{ Age of child in months } \\
\hline $0-1$ & 191 & 32.7 \\
\hline $2-3$ & 217 & 37.2 \\
\hline $4-5$ & 176 & 30.1 \\
\hline \multicolumn{3}{|l|}{ Sex of child } \\
\hline Male & 286 & 49 \\
\hline Female & 298 & 51 \\
\hline \multicolumn{3}{|l|}{ Religion of Mother } \\
\hline Orthodox Christian & 264 & 45.2 \\
\hline Protestant & 285 & 48.8 \\
\hline Muslim & 27 & 4.6 \\
\hline Others & 8 & 1.4 \\
\hline \multicolumn{3}{|c|}{ Mothers educational status } \\
\hline Never attend school & 262 & 46.0 \\
\hline Primary and above & 308 & 54.0 \\
\hline \multicolumn{3}{|l|}{ Marital status } \\
\hline Single & 10 & 1.7 \\
\hline Married & 560 & 95.9 \\
\hline Divorced/separated & 14 & 2.4 \\
\hline \multicolumn{3}{|l|}{ Mothers occupation } \\
\hline Farmer & 30 & 5.2 \\
\hline Employed & 9 & 1.5 \\
\hline Self-employed & 36 & 6.2 \\
\hline House wife & 498 & 85.4 \\
\hline Others & 10 & 1.7 \\
\hline
\end{tabular}

birth. Only $35.3 \%$ of the mothers had got support from anyone (health workers, health extension workers, volunteers, family members, neighbors and friends) within the first $1 \mathrm{~h}$ of birth. Three quarters $(76.1 \%, n=190 / 249)$ of these mothers have got the support in the nearby health facilities from health staff or health extension workers within the first $1 \mathrm{~h}$ of birth or more.

\section{Breastfeeding practices}

Almost all (99.5\%) of the infants were still breastfeeding during the survey period but only $88.0 \%$ of the mothers exclusively breastfed in the past $24 \mathrm{~h}$ of the survey date (Table 2). The prevalence of exclusive breastfeeding was relatively high among infants $0-1$ months old (95.3\%) (Fig. 1). Most of the mothers (82.6\%) initiated 
Table 2 Infant feeding and health service characteristics among mothers of infants less than 6 months of age, Tigray \& SNNPR,

$(n=584)$

Variables

Yes

Numbers (n) Percent (\%)

Frequency of ANC visits

527

90.4

Once

38

Twice

81

3 times

137

$\geq 4$ times

263

Breastfeeding counseling during pregnancy

Yes

340

Place of Delivery

Home

Health facility

Mode of delivery

Vaginal delivery

Did anyone help you with breastfeeding?

Yes

Timing of support on breastfeeding received

No support

Within $1 \mathrm{~h}$

Within $24 \mathrm{~h}$

After $24 \mathrm{~h}$

10

Where did you get the support?

$$
\text { Home }
$$

Health facility

Initiation of breastfeeding

Within $1 \mathrm{~h}$

Above $1 \mathrm{~h}$

Prelacteal feeding

Yes

Frequency of breastfeeding

$<8$ times per day

$\geq 8$ times per day

Colostrum feeding

Yes

Is the child still breastfeeding?

Yes

Breastfeeding problem

Yes

$$
20
$$

Mother's knowledge of breastfeeding initiation

Within $1 \mathrm{~h}$

515

Within $24 \mathrm{~h}$

66
Table 2 Infant feeding and health service characteristics among mothers of infants less than 6 months of age, Tigray \& SNNPR, $(n=584)$ (Continued)

\begin{tabular}{lcc}
\hline Variables & Numbers $(\boldsymbol{n})$ & Percent (\%) \\
\hline Mother's knowledge about colostrum feeding & \\
Discarding & 120 & 20.6 \\
Feeding to the new baby & 462 & 79.4 \\
Exclusive breastfeeding practices & & \\
Yes & 513 & 88.0 \\
\hline
\end{tabular}

breastfeeding within the first $1 \mathrm{~h}$ of birth and 1.5\% mothers gave prelacteal foods (plain water, sugar/glucose water, raw butter and infant formula) within the first few hours of birth (Table 2). The majority (88.3\%) of the mothers gave the first breast milk (Colostrum) to their young babies while the rest $11.7 \%$ were discarded it. Ninety-three percent of the mothers breastfed the child more than eight times per day.

Mother's awareness on timely initiation of breastfeeding and colostrum feeding were assessed and $88.6 \%$ of the mothers knew that breastfeeding should be initiated within the first 1 hour of birth (Table 2). More than three quarters (79.4\%) of the mothers believed that colostrum should be given to the new baby while the rest $20.6 \%$ of the mothers believed that it has to be discarded before the child starts breastfeeding (Table 2).

Bivariate and multivariable analysis of sociodemographic, infant feeding practices and health services related factors affecting exclusive breastfeeding were carried out. Age of the infant, marital status of mothers, breastfeeding counseling during pregnancy and place of delivery have showed an association with practices of exclusive breastfeeding in the past $24 \mathrm{~h}$. The multivariate analysis revealed that infants less than 2 months of age were four times $(\mathrm{AOR}=4.47,95 \% \mathrm{CI} 2.41,8.27)$ more likely to be exclusively breastfed than $3-5$ months old. The likelihood of practices of exclusive breastfeeding was four times $(\mathrm{AOR}=4.35,95 \% \mathrm{CI} 1.50,12.67)$ higher among married women than the unmarried. The odds of practice of exclusive breastfeeding was double among mothers who gave birth in health facilities $(\mathrm{AOR}=2.07$, 95\% CI 1.15, 3.73) and received breastfeeding counseling during pregnancy $(\mathrm{AOR}=2.23,95 \% \mathrm{CI} 1.26,3.96)$ as compared to their counterparts (Table 3).

\section{Discussion}

The results of the study showed a prevalence of EBF of 88.0\% (95\% CI 84.9-90.4\%) which was close to the WHO recommendations of $90 \%$. Age of the infant, marital status of the mothers, breastfeeding counseling during pregnancy and place of delivery were identified as significantly associated factors of exclusive breastfeeding 


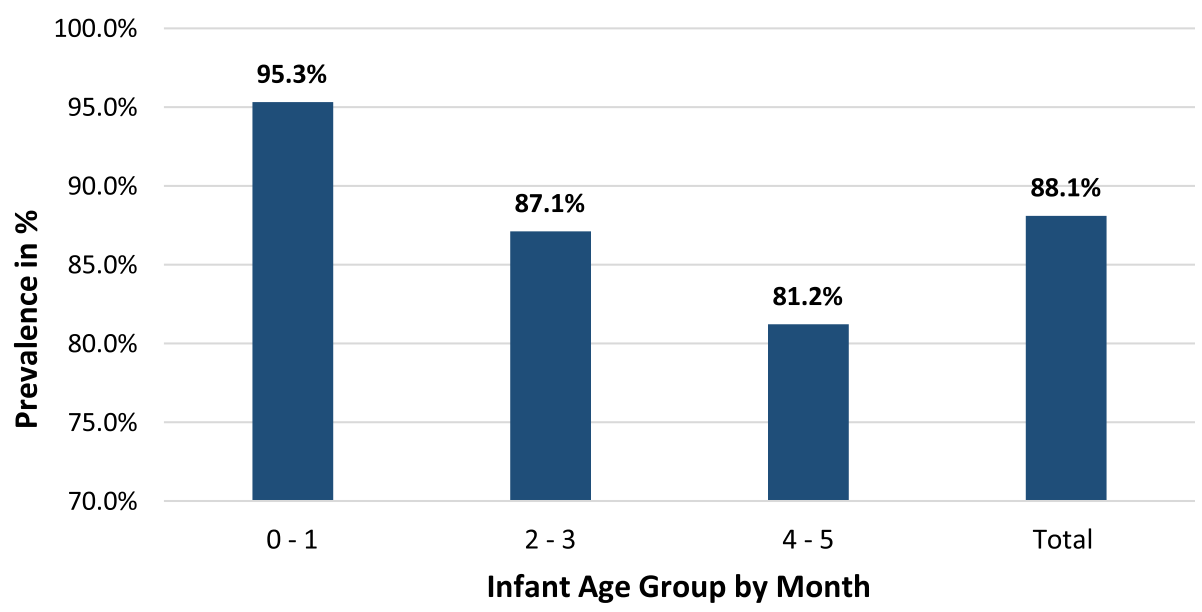

Fig. 1 Prevalence of exclusive breastfeeding by age group of infants less than 6 months of age, SNNPR \& Tigray Region, $(n=584)$

practice among mothers of infants less than 6 months of age in the past $24 \mathrm{~h}$ preceding the survey date.

The prevalence of EBF among rural mothers in SNNPR and Tigray region was much higher than the national average of EDHS 2011 (52\%), the targets of HSDP IV of the Federal Ministry of Health of Ethiopia (70\%) for 2015 [19], average estimates for Eastern and Southern African region (47\%) and developing countries (39\%) [8]. It was also much higher than cross-sectional studies conducted in some parts of Ethiopia [14-17]. This might attribute to the variations in breastfeeding promotion interventions of the health extension system with the support of the Integrated Family Health Program (IFHP) of Alive \& Thrive and others. The current finding was also higher than EBF in Nigeria [10, 21], rural Egypt [22], Uganda [11], East and South East Asia countries [23]. The variation can be explained by time of the study, study design, variations in dietary/EBF assessment method, age distribution of infants included in the study, sociodemographic, economic and cultural differences across the study areas.

In this study, infant age, delivery place, marital status of the mother and breastfeeding counseling during pregnancy were identified as associated factors with EBF in rural areas of SNNP and Tigray regions. Previous studies conducted in Ethiopia and other countries indicated that sex of the infant [21, 22], age of the mother [15, 22, 24], maternal education $[10,18,24]$ occupation of the mother [14-17], ANC [10, 14] and PNC [14, 15] practices of the mother were reported as predictors of EBF among infants less than 6 months old. However, none of these factors were associated with EBF in this study which could be due to the socio-cultural differences on breastfeeding among the study participants, study design or the sample size might not be able to capture the association between the aforementioned factors and exclusive breastfeeding.

Infants less than 3 months of age have higher chance of EBF (AOR 4.47, 95\% CI 2.41, 8.27) than the older infants. Research findings from Nigeria [7, 10, 21], Canada $[24]$ and Ethiopia $[15,16,18]$ were also in line with this study confirming that EBF decreases significantly as age of the infant increases. This can be explained by the traditional postpartum care provided to the mother within the few months after birth which gives higher contact with the infant to breastfeed, as the mothers stay at home and are less engaged in the household chores.

Married mothers practiced EBF four times (AOR 4.35, $95 \%$ CI 1.50, 12.67) higher than unmarried mothers. Evidences from Tanzania [25], Norway [26] and Canada [24] supported the current finding. The possible reason could be married mothers get support to practice EBF from their partners and other family members. In contrary, previous study conducted in Ethiopia has shown unmarried mothers practiced significantly higher EBF (AOR 2.3, 95\% CI 1.1, 4.7) than married mothers [18]. This might be due to differences in study area, design and sample size.

Mothers who gave birth in health facilities practiced EBF twice more (AOR 2.07, 95\% CI 1.15, 3.73) than the mothers who delivered at home. This result was supported by reports from Uganda [11], Ghana [12] and Ethiopia [15, 17]. This could be explained as mothers who give birth in health facilities have more opportunities to obtain breastfeeding support including counselling on the benefits of breastfeeding, correct positioning and attachment. The mothers could have a better chance to get better information of exclusive breastfeeding from the health facilities because of the availability of IEC/ BCC (Information Education Communication or 
Table 3 Association of sociodemographic, infant feeding practices and health services related characteristics with EBF of infants less than 6 months of age, SNNPR \& Tigray Region, $(n=572)$

\begin{tabular}{|c|c|c|c|c|}
\hline \multirow[t]{2}{*}{ Variables } & \multicolumn{2}{|c|}{ Exclusive Breastfeeding } & \multirow{2}{*}{$\begin{array}{l}\text { COR } \\
\text { Cl (95\%) }\end{array}$} & \multirow{2}{*}{$\begin{array}{l}\text { AOR } \\
\text { Cl (95\%) }\end{array}$} \\
\hline & No $(n, \%)$ & Yes $(n, \%)$ & & \\
\hline \multicolumn{5}{|l|}{ Age of mothers in years } \\
\hline $15-29$ & $34(9.9 \%)$ & 309 (90.1\%) & $1.75(0.94,3.25)$ & $1.69(0.97,2.95)$ \\
\hline $30-49$ & $35(14.8 \%)$ & $202(85.2 \%)$ & 1.00 & 1.00 \\
\hline \multicolumn{5}{|l|}{ Age of child in months } \\
\hline $0-2$ & $17(5.6 \%)$ & $288(94.4 \%)$ & $4.39(2.34,8.24)^{* * *}$ & $4.47(2.41,8.27)^{* * *}$ \\
\hline $3-5$ & $53(19.1 \%)$ & 225 (80.9\%) & 1.00 & 1.00 \\
\hline \multicolumn{5}{|l|}{ Sex of child } \\
\hline Male & $38(13.3 \%)$ & $247(86.7 \%)$ & $0.96(0.55,1.69)$ & - \\
\hline Female & $32(10.7 \%)$ & $266(89.3 \%)$ & 1.00 & \\
\hline \multicolumn{5}{|c|}{ Mothers' educational status } \\
\hline Never attend school & $34(13.0 \%)$ & $228(87.0 \%)$ & 1.00 & - \\
\hline Primary and above & $32(10.4 \%)$ & 275 (89.6\%) & $0.97(0.53,1.76)$ & \\
\hline \multicolumn{5}{|l|}{ Mothers' occupation } \\
\hline Working mothers & $11(13.1 \%)$ & $73(86.9 \%)$ & 1.00 & \\
\hline House wife & $58(11.6 \%)$ & $440(88.4 \%)$ & $1.09(0.50,2.39)$ & - \\
\hline \multicolumn{5}{|l|}{ Marital status } \\
\hline Unmarried & $6(26.1 \%)$ & 17 (73.9\%) & 1.00 & 1.00 \\
\hline Married & $64(11.4 \%)$ & $496(88.6 \%)$ & $5.25(1.64,6.79)^{* *}$ & $4.35(1.50,12.67)^{* *}$ \\
\hline \multicolumn{5}{|l|}{ ANC follow up } \\
\hline No & $6(10.7 \%)$ & $50(89.3 \%)$ & 1.00 & 1.00 \\
\hline Yes & $63(12.0 \%)$ & $463(88.0 \%)$ & $0.48(0.17,1.30)$ & $0.43(0.16,1.14)$ \\
\hline \multicolumn{5}{|c|}{ Breastfeeding counseling during Pregnancy } \\
\hline No & $37(15.4 \%)$ & $204(84.6 \%)$ & 1.00 & 1.00 \\
\hline Yes & $32(9.4 \%)$ & $308(90.6 \%)$ & $2.16(1.16,4.02)^{*}$ & $2.23(1.26,3.96)^{* *}$ \\
\hline \multicolumn{5}{|l|}{ Place of delivery } \\
\hline Home & $41(15.6 \%)$ & $222(84.4 \%)$ & 1.00 & 1.00 \\
\hline Health facility & $28(8.8 \%)$ & $289(91.2 \%)$ & $2.20(1.13,3.29)^{*}$ & $2.07(1.15,3.73)^{*}$ \\
\hline \multicolumn{5}{|l|}{ Mode of delivery } \\
\hline Vaginal delivery & $67(11.8 \%)$ & $503(88.2 \%)$ & $3.21(0.57,17.97)$ & $3.22(0.60,17.27)$ \\
\hline Cesarean section & $3(23.1 \%)$ & $10(76.9 \%)$ & 1.00 & 1.00 \\
\hline \multicolumn{5}{|l|}{ Initiation of breastfeeding } \\
\hline Within $1 \mathrm{~h}$ & $50(10.4 \%)$ & $429(89.6 \%)$ & $1.66(0.84,3.27)$ & $1.72(0.90,3.29)$ \\
\hline Above $1 \mathrm{~h}$ & $18(18.0 \%)$ & $82(82.0 \%)$ & 1.00 & 1.00 \\
\hline \multicolumn{5}{|l|}{ Prelacteal feeding } \\
\hline No & $66(11.5 \%)$ & $506(88.5 \%)$ & $4.08(0.89,18.68)$ & $4.33(0.98,19.09)$ \\
\hline Yes & $3(33.3 \%)$ & $6(66.7 \%)$ & 1.00 & 1.00 \\
\hline \multicolumn{5}{|l|}{ Colostrum feeding } \\
\hline No & $12(17.6 \%)$ & $56(82.4 \%)$ & 1.00 & \\
\hline Yes & $57(11.1 \%)$ & 457 (88.9\%) & $1.32(0.58,2.99)$ & - \\
\hline \multicolumn{5}{|l|}{ Breastfeeding problem } \\
\hline No & $67(11.9 \%)$ & 495 (88.1\%) & $1.20(0.24,6.13)$ & - \\
\hline Yes & $3(15.0 \%)$ & $17(85.0 \%)$ & 1.00 & \\
\hline
\end{tabular}


Table 3 Association of sociodemographic, infant feeding practices and health services related characteristics with EBF of infants less than 6 months of age, SNNPR \& Tigray Region, $(n=572)$ (Continued)

\begin{tabular}{lllll}
\hline Variables & \multicolumn{2}{l}{ Exclusive Breastfeeding } & COR & AOR \\
\cline { 2 - 3 } & No $(n, \%)$ & Yes $(n, \%)$ & & Cl (95\%) \\
\hline Did anyone help you with breastfeeding? & $43(13.0 \%)$ & $288(87.0 \%)$ & 1.00 & - \\
No & $26(10.4 \%)$ & $224(89.6 \%)$ & $0.84(0.43,1.63)$ & - \\
Yes &
\end{tabular}

${ }^{*} P<0.05, * * * 0.01, * * * P<0.001$

COR Crude Odds Ratio, AOR Adjusted Odds Ratio, CI Confidence Interval

Behavior Change Communication) materials in the facilities. However, a national study conducted in Canada differed with the findings of the current study because mothers who preferred to deliver at home were more likely to practice EBF (AOR 5.29, 95\% CI 2.95, 9.46) [24]. This could be due to the differences of the health services delivered at various settings.

Mothers who received breastfeeding counseling during pregnancy practiced EBF double (AOR 2.23, 95\% CI $1.26,3.96)$ of their counterparts which is consistent with reports from Ethiopia [14, 15, 17] and Uganda [11]. The possible reason could be the information provided during counseling may help the mothers to increase their awareness about the importance of breastfeeding that brought attitudinal changes on exclusive breastfeeding. The expansion of health facilities in rural areas with trained health professionals, and the involvement of the Women Development Army (WDA) in the health extension intervention, who transmit messages of appropriate breastfeeding to the mothers could contribute a lot.

\section{Limitations of the study}

This study shares the limitation of any other crosssectional studies of drawing cause and effect relationship between the factors and the prevalence of exclusive breastfeeding in the study area. It was not possible to analyze the prevalence of EBF for the two regions separately as the sample size were calculated for the combined regions as the domain of IFHP project area. The prevalence of EBF might be overestimated due to the nature of the method used for data collection: the 24-h recall method. Some of the independent variables were not associated with the dependent variable which has been reported as factors associated with exclusive breastfeeding in many studies. This might be due to the sample size which was not able to justify the relationship between the factors and the dependent variable. This study is representative of rural parts of the two regions; hence it cannot be generalized to the entire population of the two regions. Therefore, the interpretation of the study should consider the strengths and the limitations of the study.

\section{Conclusions}

The prevalence of exclusive breastfeeding among mother of infants less than 6 months of age in the two regions was relatively high as compared with previous studies but was in line with the WHO recommendations. In this study, exclusive breastfeeding practices of mothers in the past $24 \mathrm{~h}$ were affected by infant age, marital status of mothers, place of delivery and breastfeeding counseling during pregnancy. Devising appropriate Social and Behavior Change Communication (SBCC) strategies on breastfeeding messaging/counseling and support in addressing poor breastfeeding practices through the existing government-led health intervention packages such as the community-based health extension program are recommended. Breastfeeding messaging during antenatal care and postnatal care, breastfeeding support during pregnancy, and establishment of mother to mother support groups could be the potential areas for improvement.

\section{Acknowledgements \\ The authors express their gratitude to Addis Continental Institute of Public Health for collecting the data and thank all survey participants in the evaluation study. \\ Research reported in this publication was supported by the Fogarty International Center and National Institute of Mental Health, of the National Institutes of Health under Award Number D43 TW010543. The content is solely the responsibility of the authors and does not necessarily represent the official views of the National Institutes of Health.}

\section{Authors' contributions}

$\mathrm{DH}$ and $\mathrm{AWT}$ conceived the research idea. DH analyzed the data, interpreted the results and drafted the manuscript. AWT interpreted the results and gave critical comments at each stage of manuscript development. All authors critically reviewed the manuscript and approved for submission.

\section{Funding}

The Bill \& Melinda Gates Foundation, through Alive \& Thrive, managed by FHI 360 funded this evaluation study. Additional financial support was obtained from the CGIAR Research Program on Agriculture for Nutrition and Health (A4NH), led by the International Food Policy Research Institute (IFPRI). No financial support was received to write this specific paper.

\section{Availability of data and materials}

The data used and/ or analysed for the current study are available from the second author upon reasonable request Please contact Dr. Amare Worku to request the data at adtadesse@gmail.com.

Ethics approval and consent to participate

Ethical clearance was provided by the institutional ethical review board of Addis Continental Institute of Public Health (ACIPH) (ACIPH/IRB/056/08). 
Mothers were informed about the study aims and survey procedures. Verbal consent was obtained from participants prior to the interviews.

\section{Consent for publication}

Not applicable.

\section{Competing interests}

The authors declare that they have no competing interests.

\section{Author details}

Save the Children South Sudan, Juba, South Sudan. ${ }^{2}$ Department of Reproductive Health, Population and Nutrition, Addis Continental Institute of Public Health, Addis Ababa, Ethiopia. ${ }^{3}$ Department of Global Health and Population, Harvard T.H. Chan School of Public Health, Boston, MA, USA.

Received: 24 March 2019 Accepted: 30 March 2020

Published online: 10 April 2020

\section{References}

1. Kramer MS, Kakuma R. Optimal duration of exclusive breastfeeding. Cochrane Database Syst Rev. 2002;1:CD003517.

2. American Academy of Pediatrics. Breastfeeding and the use of human Milk. Pediatrics. 2012;129(3):827-41.

3. Ballard O, Morrow AL. Human milk composition: nutrients and bioactive factors. Pediatr Clin N Am. 2013;60(1):49-74.

4. World Health Organization, UNICEF: Global strategy for infant and young child feeding. 2003. https://www.whoint/nutrition/publications/ infantfeeding/9241562218/en/ Accessed 1 Jan 2018.

5. Jones G, Steketee RW, Black RE, Bhutta ZA, Morris SS, et al. How many child deaths can we prevent this year? Lancet. 2003;362(9377):65-71.

6. Adewuyi E, Adefemi K. Breastfeeding in Nigeria: a systematic review. Int J Community Med Public Health. 2016;3(2):385-96.

7. Stuebe A. The risks of not breastfeeding for mothers and infants. Rev Obstet Gynecol. 2009;2(4):222-31.

8. Cai X, Wardlaw T, Brown DW. Global trends in exclusive breastfeeding. Int Breastfeed J. 2012;7:12.

9. Central Statistical Agency, Inner City Fund International. Ethiopia Demographic and Health Survey 2016. Addis Ababa and Rockville: Central Statistical Agency of Ethiopia and ICF International Addis Ababa. https:// dhsprogram.com/pubs/pdf/SR241/SR241.pdf.

10. Ogbo FA, Agho KE, Page A. Determinants of suboptimal breastfeeding practices in Nigeria: evidence from the 2008 demographic and health survey. BMC Public Health. 2015;15:259.

11. Bbaale E. Determinants of early initiation, exclusiveness, and duration of breastfeeding in Uganda. J Health Popul Nutr. 2014;32(2):249-60.

12. Aidam BA, Perez-Escamila R, Lartey A, J Aidam BA. Factors associated with exclusive breastfeeding in Accra, Ghana. Eur J Clin Nutr. 2005;59(6):789-96.

13. Hector D, King L, Webb K, Heywood P. Factors affecting breastfeeding practices: applying a conceptual framework. New South Wales Public Health Bull. 2005;16(3-4):52-5.

14. Sonko A, Tadesse AW. Prevalence and predictors of exclusive breastfeeding for the first six months of life among women in Halaba special woreda, southern nations, nationalities and peoples' region/SNNPR/, Ethiopia: a community based cross-sectional study. Arch Public Health. 2015;73:53.

15. Asemahagn MA. Determinants of exclusive breastfeeding practices among mothers in Azezo district, Northwest Ethiopia. Int Breastfeed J. 2016;11:22.

16. Setegn T, Belachew T, Gerbaba M, et al. Factors associated with exclusive breastfeeding practices among mothers in Goba district, south East Ethiopia: a cross-sectional study. Int Breastfeed J. 2012;7:17.

17. Asfaw MM, Argaw MD, Kefene ZK. Factors associated with exclusive breastfeeding practices in Debre Berhan District, Central Ethiopia: a cross sectional community based study. Int Breastfeed J. 2015;10:23.

18. Alemayehu T, Haidar J, Habte D. Determinants of exclusive breastfeeding practices in Ethiopia. Ethiop J Health Dev Ethiop J Health Dev. 2009;23(1):12-8

19. Central Statistical Agency, Inner City Fund International. Ethiopia Demographic and Health Survey 2011. Addis Ababa and Calverton: Central Statistical Agency and ICF International; 2012.

20. WHO. Indicators for assessing infant and young child feeding practices. 2008. http://www.who.int/maternal_child_adolescent/documents/97892415 99757/en/ Accessed on 20 Sept 2018
21. Agho KE, Dibley MJ, Odiase Il, et al. Determinants of exclusive breastfeeding in Nigeria. BMC Pregnancy Childbirth. 2011;11:2

22. Al Ghwass MME, Ahmed D. Prevalence and predictors of 6-month exclusive breastfeeding in a rural area in Egypt. Breastfeed Med. 2011;6(4):191-6.

23. Senarath $U$, Agho K. Infant and young child feeding indicators across nine east and southeast Asian countries: an analysis of National Survey Data 2000-2005. Public Health Nutr. 2010;13:1296-303.

24. Al-Sahab B, Lanes A, Feldman M, et al. Prevalence and predictors of 6month exclusive breastfeeding among Canadian women: a national survey. BMC Pediatr. 2010;10:20.

25. Mgongo M, Mosha MV, Uriyo JG, et al. Prevalence and predictors of exclusive breastfeeding among women in Kilimanjaro region, Northern Tanzania: a population based cross-sectional study. Int Breastfeed J. 2013;8:12

26. Lande B, Andersen LF, Baerug A, Trygg KU, Lund-Larsen K, Veierød MB, Bjørneboe GE. Infant feeding practices and associated factors in the first six months of life: the Norwegian infant nutrition survey. Acta Paediatr. 2003; 92(2):152-61.

\section{Publisher's Note}

Springer Nature remains neutral with regard to jurisdictional claims in published maps and institutional affiliations.
Ready to submit your research? Choose BMC and benefit from:

- fast, convenient online submission

- thorough peer review by experienced researchers in your field

- rapid publication on acceptance

- support for research data, including large and complex data types

- gold Open Access which fosters wider collaboration and increased citations

- maximum visibility for your research: over $100 \mathrm{M}$ website views per year

At BMC, research is always in progress.

Learn more biomedcentral.com/submissions 